IRRITABLE BOWEL SYNDROME

\title{
Effect of a corticotropin releasing hormone receptor antagonist on colonic sensory and motor function in patients with irritable bowel syndrome
}

\author{
Y Sagami, Y Shimada, J Tayama, T Nomura, M Satake, Y Endo, T Shoji, K Karahashi, M Hongo, \\ S Fukudo
}

Gut 2004;53:958-964. doi: 10.1136/gut.2003.018911

See end of article for authors' affiliations

Correspondence to: Professor S Fukudo, Department of Behavioural Medicine, Tohoku University Graduate School of Medicine, 2-1 Seiryo, Aoba, Sendai, 980-8575, Japan; sfukudo@mail.tains. tohoku.ac.jp

Accepted for publication 25 November 2003

\begin{abstract}
Background and aims: Corticotropin releasing hormone $(\mathrm{CRH})$ is a major mediator of the stress response in the brain-gut axis. Irritable bowel syndrome (IBS) is presumed to be a disorder of the brain-gut link associated with an exaggerated response to stress. We hypothesised that peripheral administration of $\alpha$-helical CRH (ahCRH), a non-selective CRH receptor antagonist, would improve gastrointestinal motility, visceral perception, and negative mood in response to gut stimulation in IBS patients.

Methods: Ten normal healthy subjects and 10 IBS patients, diagnosed according to the Rome II criteria, were studied. The tone of the descending colon and intraluminal pressure of the sigmoid colon were measured at baseline, during rectal electrical stimulation (ES), and at recovery after administration of saline. Visceral perception after colonic distension or rectal ES was evaluated as threshold values on an ordinate scale. The same measurements were repeated after administration of $\alpha \mathrm{hCRH}(10 \mu \mathrm{g} / \mathrm{kg})$.

Results: ES induced significantly higher motility indices of the colon in IBS patients compared with controls. This response was significantly suppressed in IBS patients but not in controls after administration of ahCRH. Administration of ahCRH induced a significant increase in the barostat bag volume of controls but not in that of IBS patients. ahCRH significantly reduced the ordinate scale of abdominal pain and anxiety evoked by ES in IBS patients. Plasma adrenocorticotropic hormone and serum cortisol levels were generally not suppressed by ahCRH.

Conclusion: Peripheral administration of ahCRH improves gastrointestinal motility, visceral perception, and negative mood in response to gut stimulation, without affecting the hypothalamo-pituitary-adrenal axis in IBS patients.
\end{abstract}

Abbreviations: IBS, irritable bowel syndrome; $\mathrm{CRH}$, corticotropin releasing hormone; $\alpha \mathrm{hCRH}, \alpha$-helical $\mathrm{CRH}$; ES, electrical stimulation; ACTH, adrenocorticotropic hormone; ENS, enteric nervous system 


\section{Cannulation and recording assemblies}

On the evening before cannulation, each subject ingested a preparation consisting of a $125 \mathrm{ml}$ solution of magnesium citrate (13.6\%) and $2.5 \mathrm{mg}$ of sodium picosulphate to reduce faecal effluent. Based on earlier reports ${ }^{24}$ and our previous studies, ${ }^{16-18}$ this bowel preparation was unlikely to affect colonic motility. At 09:00 the next day, a polyethylene catheter with a cylindrical barostat bag (Synectics Medical, Stockholm, Sweden) and three transducers (Gaeltec, Dunvegan, UK) were inserted into the proximal portion of the descending colon under colonoscopy. The catheter had a separate lumen for measuring pressure in the barostat bag which was set in the proximal portion of the descending colon approximately $65 \mathrm{~cm}$ from the anus. The three transducers were set in the descending, proximal sigmoid, and mid sigmoid colon, approximately $50 \mathrm{~cm}, 45 \mathrm{~cm}$, and $40 \mathrm{~cm}$ from the anus, respectively. A bipolar electrode catheter for electrical stimulation of the mucosa was set in the rectum ( $15 \mathrm{~cm}$ from the anus) under fluoroscopic control. The position of the catheters was confirmed before and after the study session. The three transducers and the barostat bag catheter were each connected to an analogue digital converter (PC-Polygram; Synectics, Stockholm, Sweden) and a visceral stimulator (Synectics). The catheter in the rectum was connected to an electronic stimulator (NEC San-Ei Instruments Ltd, Tokyo, Japan). Using a tracking technique, ${ }^{25}$ the pressure of the barostat bag was set at $10 \mathrm{~mm} \mathrm{Hg}$, except for measurement of thresholds during colonic distension. Manometric and barostat data were monitored throughout the experiment and analogue signals were digitised onto computers (PC-9801 ES, NEC; GX 1, Dell, USA). A polytetrafluoroethylene cannula was inserted into the right arm vein for blood sampling, and saline or $\alpha$-helical CRH ( $\alpha$ hCRH) was infused at a speed of $1.3 \mathrm{ml} / \mathrm{min}$.

\section{Experimental design}

Following cannulation, subjects were allowed a 60 minute adaptation period after which intracolonic pressure and bag volume were monitored for 150 minutes. Using a tracking technique, pressure sensory thresholds were measured for 10 minutes before bolus saline injection (tracking 0: T0). The experiment consisted of two 70 minute stages: the first with administration of saline and the second with administration of ahCRH (Bachem, Switzerland), a non-selective CRH receptor antagonist (fig 1). Both stages consisted of four periods: baseline (B1, B2), rectal electrical stimulation (ES1, $E S 2)$, recovery $(R 1, R 2)$, and tracking (T1, T2), with durations of 20, approximately 20, 20, and 10 minutes, respectively. In the first stage, saline was injected as a bolus $(20 \mathrm{ml})$ followed by continuous infusion for the rest of the period. In the second stage, ahCRH was given as a bolus $(2 \mu \mathrm{g} / \mathrm{kg})$ followed by continuous infusion at $8 \mu \mathrm{g} / \mathrm{kg}$ for the rest of the period. The total dose of $\alpha$ hCRH $(10 \mu \mathrm{g} / \mathrm{kg})$ has been shown to inhibit stress induced exaggeration of colonic motility in animal experiments. ${ }^{10}$ Although subjects were informed of the use of ahCRH in this study, they could not predict the timing of its administration as saline was continuously infused. Blood samples were drawn from the intravenous cannula after each period. Plasma and serum were obtained by centrifugation of the samples at $3000 \mathrm{rpm}$ for five minutes, frozen, and stored at $-45^{\circ}$ for later analysis.

\section{Visceral perception to distension}

The pressure of the barostat bag was increased stepwise ( $2 \mathrm{~mm} \mathrm{Hg}$ ) from 0 to $60 \mathrm{~mm} \mathrm{Hg}$. Each inflation step lasted 10 seconds. Subsequent distensions were adjusted up or down depending on the subject's response to the previous distension. The lowest pressure of any new sensation was determined as the minimal sensory threshold (ST-D), the lowest pressure that caused any definite unpleasant sensation was defined as the discomfort threshold (DT-D), and the lowest pressure that evoked a painful sensation was defined as the pain threshold (PT-D).

\section{Rectal electrical stimulation (ES)}

Rectal ES was performed using a bipolar electrode attached to a 6F catheter (Dr Osypica GMBH, Granzach-Whylen, Germany). The two poles of the electrode were situated $10 \mathrm{~mm}$ apart. ES was applied to the rectal mucosa at a frequency of $1.0 \mathrm{~Hz}$ with an intensity ranging from 0 to $50 \mathrm{~mA}$. At the beginning of ES, sensory threshold was determined using a tracking technique. Subjects were asked to report any new sensation (minimal sensory threshold, STE), unpleasant sensation (discomfort threshold, DT-E), or painful sensation (pain threshold, PT-E). After measurement of sensory thresholds, ES was performed randomly at ST-E, DT-E, or PT-E with an intensity of $30 \mathrm{~mA}$. This intensity was chosen for comparison of responses between controls and IBS patients, and is considered high enough to evoke visceral perception. ${ }^{26}$ The intensity of ES during the second stage of the experiment was the same as that in the first stage.

\section{Ordinate scales for subjective symptoms}

Seven subjective symptoms were evaluated on a self-rating scale from 0 (none) to 10 (maximum). ${ }^{15}$ They were abdominal discomfort, abdominal pain, abdominal bloating, urgency of defecation, anxiety, perceived stress, and sleepiness. Symptoms were checked at the end of B1, R1, TR1, B2, R2, and TR2 periods. During ES, subjects were asked to report symptoms immediately after stimulation at ST-E, DT-E, or PT-E with $30 \mathrm{~mA}$.

\section{Data analysis}

The volume of the barostat bag was analysed for each period of the experiment. ${ }^{25}$ The colonic motility index was calculated by measuring the area under the pressure curve for each period using a computerised planimeter (Gastrosoft ${ }^{27}$ and the following formula:

motility index $=100(\%) \times$ area under the pressure curve $(\mathrm{mm} \mathrm{Hg} \times \mathrm{s}) /($ duration of period $\times 60 \mathrm{~s})$.

Ordinate scales for subjective symptoms were analysed in two parts for trackings and other periods of the experiment. Stored blood samples were defrosted and levels of plasma ACTH and serum cortisol were measured by radioimmunoassay. Minimal detectable values of ACTH and cortisol were $4 \mathrm{pg} / \mathrm{ml}$ and $0.64 \mu \mathrm{g} / \mathrm{dl}$, respectively, while interassay variability was $3.89 \%$ for ACTH and $2.64 \%$ for cortisol.

\section{Statistical analysis}

Data are expressed as mean (SEM) unless otherwise indicated. Differences in means between the control subjects $(\mathrm{n}=10)$ and IBS patients $(\mathrm{n}=10)$ were compared by repeated two way analysis of variance (ANOVA). The Mann-Whitney $U$ test was used to compare the two groups at specific time points. The paired $t$ test and Wilcoxon's signed rank test were used to detect significant changes within the same group. Data for colonic motility indices from a control subject and for plasma ACTH levels from another control subject were excluded due to technical problems. A p value of less than 0.05 was regarded as significant.

\section{RESULTS}

\section{Changes in barostat bag volume}

There was a significant group (controls $v$ IBS patients) to period interaction in the volume of the barostat bag (two way ANOVA, $\mathrm{F}=3.39, \mathrm{p}=0.0075$ ) (fig 2). Basal bag volume in IBS patients tended to be smaller than that in controls. A significant increase in bag volume was observed in the 


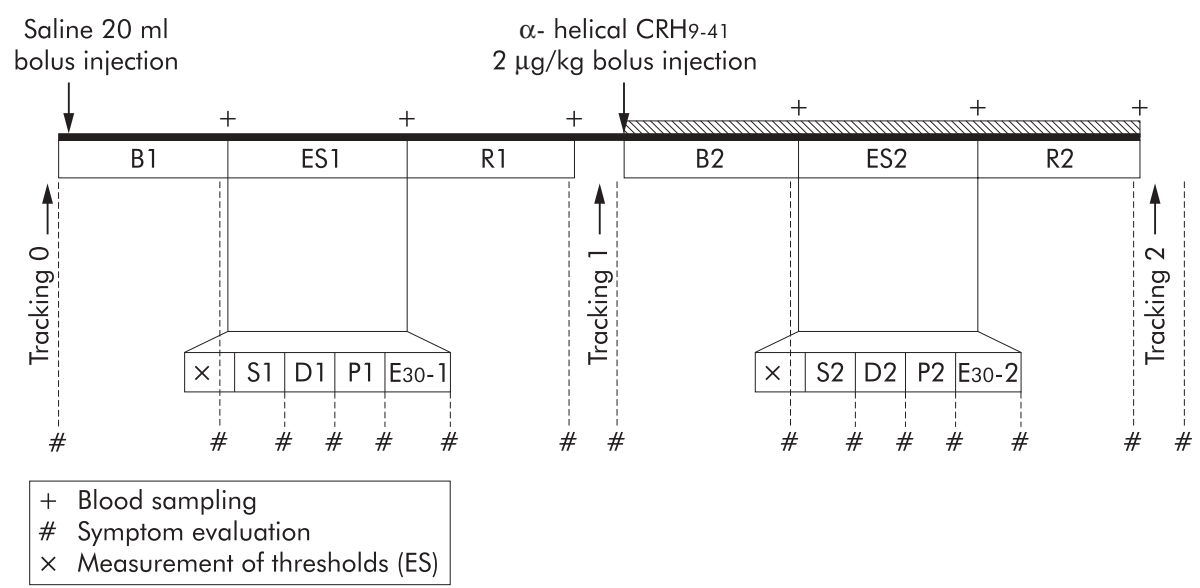

Figure 1 Experimental design. The first stage consisted of B1 (baseline), ES1 (electrical stimulation of the rectum), and R1 (recovery). The second stage (hatched bar) consisted of B2 (baseline), ES2 (electrical stimulation of the rectum), and R2 (recovery). Response to ES consisted of measurements of thresholds following randomised stimulation at minimal sensory thresholds (S1, S2), discomfort thresholds (D1, D2), and pain thresholds (P1, P2), with an intensity of $30 \mathrm{~mA}$ (E30-1, E30-2). Visceral perception to colonic distension was evaluated before the first stage (tracking 0), during the first stage (tracking 1), and during the second stage (tracking 2). Ordinate scales were obtained after the period of tracking 0, B1, ES1 (S1, D1, P1, E30-1), R1, tracking 1, B2, ES2 (S2, D2, P2, E30-2), R2, and tracking 2.

second stage of the experiment among controls (from 105.8 (30.5) $\mathrm{ml}$ at B1 to 148.3 (37.4) $\mathrm{ml}$ at $\mathrm{B} 2 ; \mathrm{p}=0.0038$ ) but not among IBS patients. In IBS patients, ES during the first stage of the experiment significantly reduced bag volume from 64.9 (12.3) $\mathrm{ml}$ at Bl to $54.5(13.2) \mathrm{ml}$ at ESl $(\mathrm{p}=0.014)$. Even during administration of $\alpha$ hCRH, ES significantly reduced bag volume in IBS patients from 75.5 (12.0) $\mathrm{ml}$ at B2 to 69.6 (12.7) $\mathrm{ml}$ at ES2 $(\mathrm{p}=0.0041)$. In contrast, ES failed to reduce bag volume among controls.

\section{Changes in motility indices of the colon}

There was a trend group (controls $v$ IBS patients) effect in motility indices of the mid sigmoid colon (two way ANOVA, $\mathrm{F}=2.97, \mathrm{p}=0.1$ ). There was no significant difference at $\mathrm{B} 1$ between controls and IBS patients. In contrast, motility indices of the mid sigmoid colon at ESI in IBS patients were

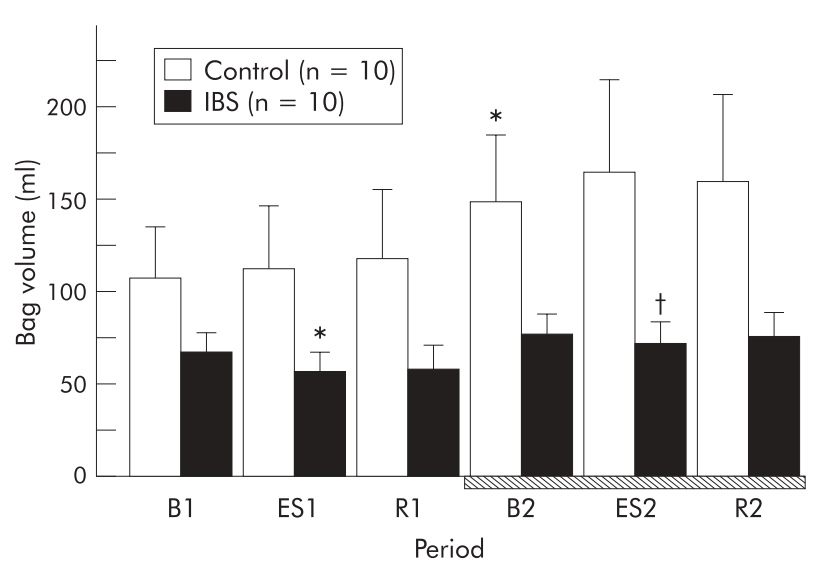

Figure 2 Increase in bag volume of the descending colon after $\alpha$-helical corticotropin releasing hormone $(C R H)_{9-41}(10 \mu \mathrm{g} / \mathrm{kg})$ administration in control subjects but not in patients with irritable bowel syndrome (IBS). Intravenous administration of $\alpha$-helical $\mathrm{CRH}_{9-41}$ is indicated by the hatched bar. Data are expressed as mean (SEM). There was a significant group to period interaction between controls and IBS patients (two way ANOVA, $p<0.05)$. B1: baseline, ES1: electrical stimulation of the rectum, and $\mathrm{R} 1$ : recovery, in the first stage of the experiment. $\mathrm{B} 2$ : baseline, ES2: electrical stimulation of the rectum, and R2: recovery in the second stage (hatched bar). ${ }^{*} p<0.05$ compared with $B 1$ by the paired $t$ test; $t p<0.05$ compared with B2 by the paired $t$ test. significantly higher than those in controls (421.5 (171.6) $v$ 124.5 (46.5); $p=0.041$ ) (fig 3). In IBS patients, motility indices of the mid sigmoid colon at ES2 were significantly lower than those at ESI or Rl $(\mathrm{p}<0.05$, fig 3$)$. There was no difference in motility indices of the mid sigmoid colon at ES2 between controls and IBS patients. The ES induced increase in motility indices in IBS patients was suppressed in the second stage of the experiment. In addition, motility indices of the mid sigmoid colon in controls were significantly decreased from $122.4(19.4)$ at B2 to 66.6 (13.7) at R2 $(\mathrm{p}=0.012)$. Motility indices of the mid sigmoid colon at R2 in IBS patients were significantly higher than those in controls (275.1 (101.9) $v 66.6$ (13.7); $\mathrm{p}=0.018)$. In the other two sites of the colon (descending and proximal sigmoid),

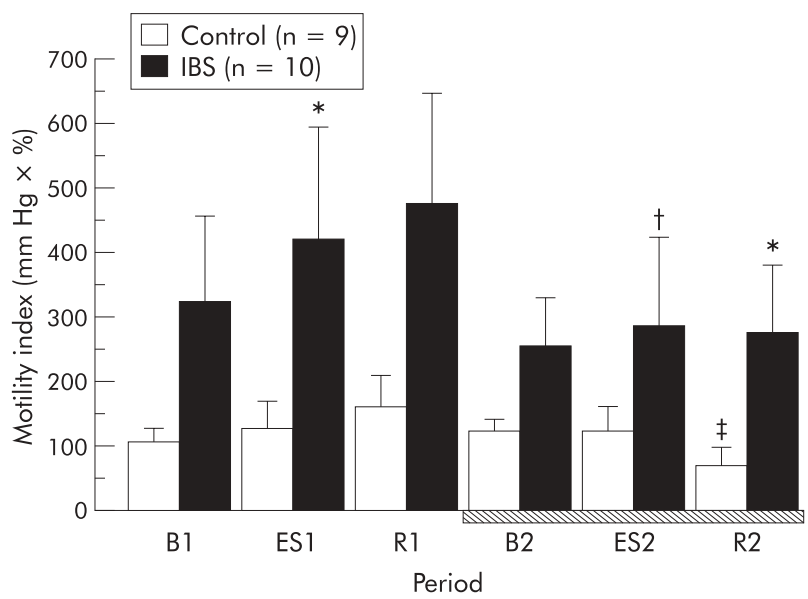

Figure 3 Electrical stimulation (ES) induced increase in motility indices of the mid sigmoid colon in irritable bowel syndrome (IBS) patients was blocked by administration of $\alpha$-helical corticotropin releasing hormone $(\mathrm{CRH})_{9-41}(10 \mu \mathrm{g} / \mathrm{kg})$. Intravenous administration of $\alpha$-helical $\mathrm{CRH}_{9-41}$ is indicated by the hatched bar. Data are expressed as mean (SEM). B1: baseline, ES1: electrical stimulation of the rectum, and R1: recovery, in the first stage of the experiment. B2: baseline, ES2: electrical stimulation of the rectum, and R2: recovery in the second stage (hatched bar). ${ }^{*} p<0.05$ compared with controls by the Mann-Whitney U test; $\uparrow p<0.05$ compared with ESI or R1 by the paired $t$ test; $\neq p<0.05$ compared with B2 by the paired $t$ test. 
Table 1 Sensory thresholds to electrical stimulation (ES) of the rectum

\begin{tabular}{llll}
\hline & $\begin{array}{l}\text { First stage } \\
\text { (saline) }\end{array}$ & $\begin{array}{l}\text { Second stage } \\
\text { (ahCRH 9-4) }\end{array}$ & p Value \\
\hline $\begin{array}{llll}\text { Control } \\
\quad \text { First sensation (E) }\end{array}$ & $18.3(3.2)$ & $19.5(3.5)$ & 0.66 \\
$\quad$ Discomfort (E) & $24.4(3.9)$ & $29.6(3.8)$ & 0.059 \\
$\quad$ Pain (E) & $30.4(3.9)$ & $36.3(4.1)$ & 0.065 \\
IBS & & & \\
$\quad$ First sensation (E) & $17.9(2.8)$ & $20.7(3.0)$ & 0.46 \\
$\quad$ Discomfort (E) & $23.7(3.6)$ & $29.0(3.6)$ & 0.13 \\
$\quad$ Pain (E) & $31.8(3.8)$ & $37.8(4.0)$ & 0.13 \\
\hline
\end{tabular}

Data are expressed as mean (SEM) (mA). There was no significant change between the two stages of the experiment by the paired $t$ test. However, all thresholds in the antagonist stage (second stage) showed higher mean values than those in the saline stage (first stage). IBS, irritable bowel syndrome; $\alpha \mathrm{hCRH}, \alpha$-helical corticotropin releasing hormone.

motility indices showed a similar pattern to that of the mid sigmoid colon at all periods (data not shown).

\section{Sensory threshold to distension or electrical stimulation}

In control subjects, the minimal sensory threshold (ST-D) significantly decreased from $25.0(2.6) \mathrm{mm} \mathrm{Hg}$ at T0 to 15.0 (1.9) $\mathrm{mm} \mathrm{Hg}$ at $\mathrm{Tl}(\mathrm{p}=0.0035)$. In addition, ST-D after administration of $\alpha$ hCRH remained similar to that at Tl (16.2 (2.4) $\mathrm{mm} \mathrm{Hg}$ at T2). Similarly, the discomfort threshold (DTD) significantly decreased from $32.0(3.1) \mathrm{mm} \mathrm{Hg}$ at TR0 to 23.4 (2.2) $\mathrm{mm} \mathrm{Hg}$ at Tl $(\mathrm{p}=0.03)$. DT-D after administration of $\alpha$ hCRH remained similar to that at TRl (25.0 (2.4) $\mathrm{mm} \mathrm{Hg}$ at T2). In contrast, the pain threshold (PT-D) at T1 (32.8 (3.1) $\mathrm{mm} \mathrm{Hg}$ ) was significantly lower than that at TR0 (38.6 (3.2) $\mathrm{mm} \mathrm{Hg} ; \mathrm{p}=0.038$ ). There was no difference between PT-D at Tl and T2 (33.4 (2.7) $\mathrm{mm} \mathrm{Hg}$ ).
In IBS patients, there was no significant difference in the minimal sensory threshold (ST-D) at TR0 (23.4 (2.9) $\mathrm{mm} \mathrm{Hg}$ ) and at TRl (20.4 (3.3) $\mathrm{mm} \mathrm{Hg})$. ST-D at T2 (15.2 (2.2) $\mathrm{mm} \mathrm{Hg}$ ) was significantly lower than that at T0 $(p=0.0002)$. The discomfort threshold (DT-D) showed a similar pattern to that of ST-D with values of 32.0 (2.5) $\mathrm{mm} \mathrm{Hg}$ at TR0, $30.6(2.8) \mathrm{mm} \mathrm{Hg}$ at $\mathrm{Tl}$, and 24.0 (3.5) $\mathrm{mm} \mathrm{Hg}$ at $\mathrm{T} 2 \quad(\mathrm{p}=0.0031)$. In contrast, the pain threshold (PT-D) at T2 $(33.6(2.8) \mathrm{mm} \mathrm{Hg})$ was significantly lower than that at T0 $(40.2(3.0) \mathrm{mm} \mathrm{Hg} ; \mathrm{p}=0.0046)$ or that at $\mathrm{Tl}$ (38.8 (2.5) $\mathrm{mm} \mathrm{Hg}$; $=0.015)$. In summary, there was no significant difference in ST-D, DT-D, or PT-D between controls and IBS patients.

In the first and second stages, there was no significant difference for any of the threshold values (ST-E, DT-E, and PT-E) to ES between controls and IBS patients, although all three thresholds tended to be higher during the second stage among both controls and IBS patients (table 1).

\section{Ordinate scale and subjective symptoms}

The ordinate scale of abdominal pain in control subjects was significantly different from that in IBS patients (two way ANOVA, $\mathrm{F}=5.18, \mathrm{p}=0.035$ ) (fig 4). In IBS patients, the ordinate scale of abdominal pain at ES2 during administration of ahCRH was significantly lower than that at ESI during administration of saline (ANOVA, $\mathrm{F}=6.84, \mathrm{p}=0.018$ ) (fig 4). However, in controls, the abdominal pain scale at ES2 did not differ from that at ESI. The ordinate scale of abdominal discomfort, abdominal bloating, or urgency for defecation showed a similar pattern to that of abdominal pain (data not shown).

The ordinate scale of anxiety showed a similar pattern to that of abdominal pain (fig 5). Two way ANOVA of the anxiety ordinate scale revealed a significant period effect $(\mathrm{F}=6.57, \mathrm{p}<0.0001)$ and a group to period interaction

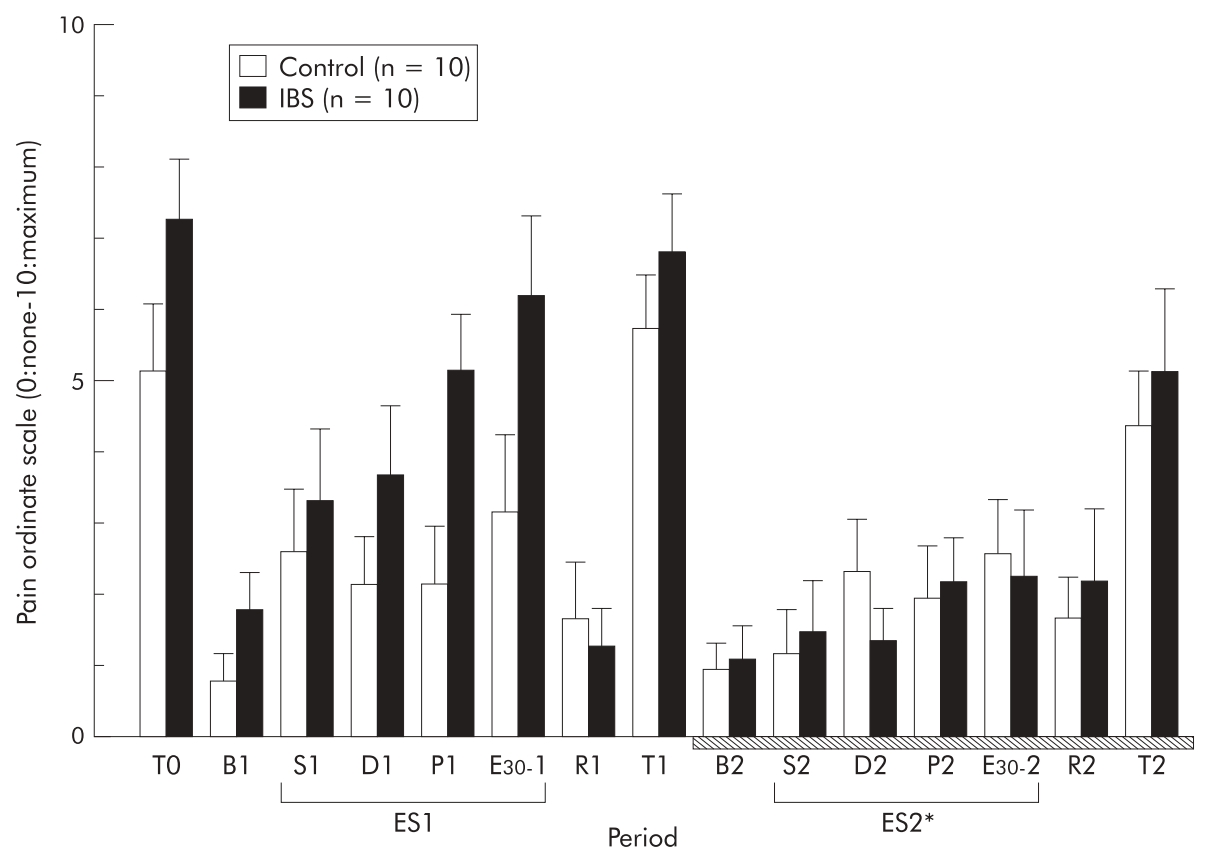

Figure 4 Changes in the ordinate scale of abdominal pain. B1: baseline, ES1: electrical stimulation of the rectum (S1: sensory threshold, D1: discomfort threshold, P1: pain threshold, E30-1: $30 \mathrm{~mA}$ ), and R1: recovery, in the first stage of the experiment. B2: baseline, ES2: electrical stimulation of the rectum (S2: sensory threshold, D2: discomfort threshold, P2: pain threshold, E30-2: $30 \mathrm{~mA}$ ), and R2: recovery, in the second stage (hatched bar). Data are expressed as mean (SEM). There was a significant group to period interaction between controls and irritable bowel syndrome (IBS) patients (two way ANOVA, $p<0.05$ ). In IBS patients, the ordinate scale of abdominal pain at ES2 was significantly lower than that at ES1 (ANOVA, $\left.{ }^{*} \mathrm{p}<0.05\right)$. 


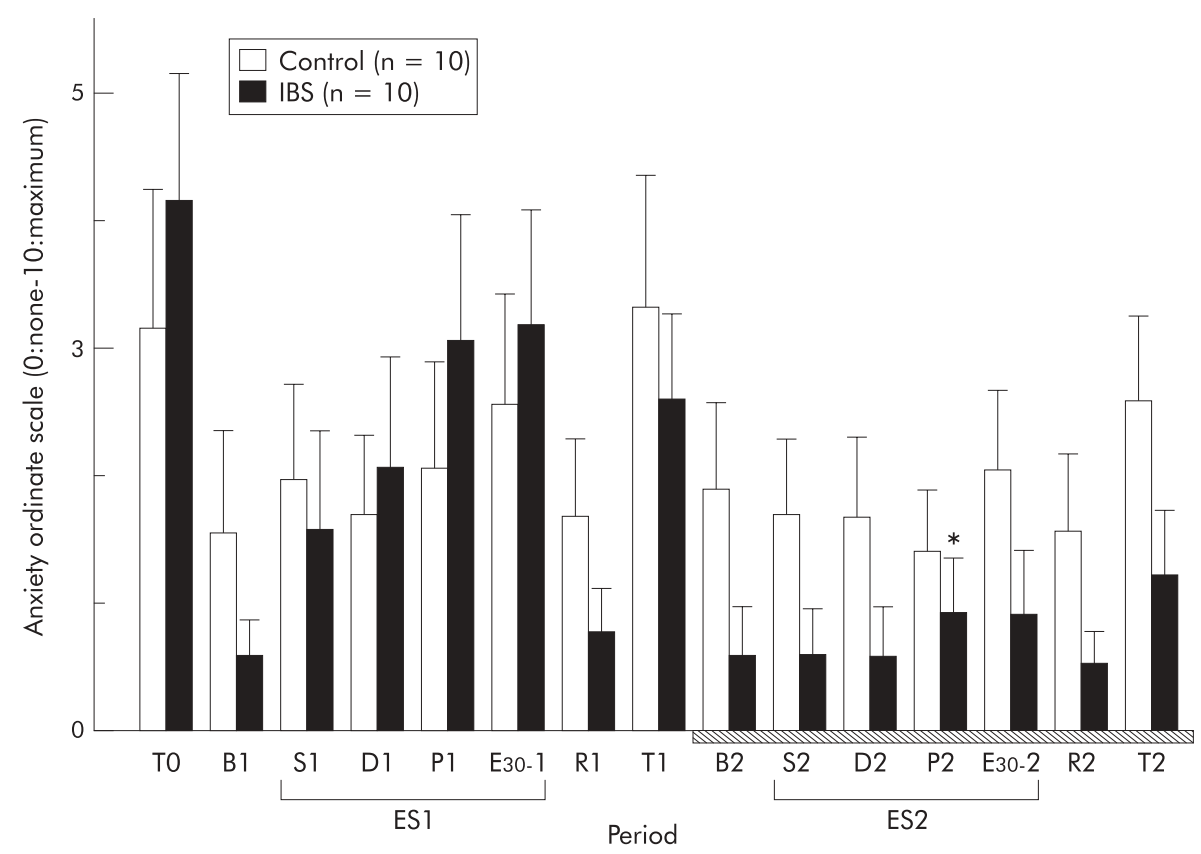

Figure 5 Changes in the ordinate scale of anxiety. B1: baseline, ES1: electrical stimulation of the rectum (S1: sensory threshold, D1: discomfort threshold, P1: pain threshold, E30-1: $30 \mathrm{~mA}$ ), and R1: recovery, in the first stage of the experiment. B2: baseline, ES2: electrical stimulation of the rectum (S2: sensory threshold, D2: discomfort threshold, P2: pain threshold, E30-2: $30 \mathrm{~mA}$ ), and R2: recovery, in the second stage (hatched bar). Data are expressed as mean (SEM). There was a significant group to period interaction between controls and IBS patients (two way ANOVA, $p<0.05$ ). In IBS patients, the ordinate scale of anxiety at P2 was significantly lower than that at P1 (Wilcoxon's signed rank test, ${ }^{*} \mathrm{p}<0.05$ ).

$(\mathrm{F}=1.89, \mathrm{p}=0.037)$ (fig 5). In IBS patients, the ordinate scale of anxiety at $\mathrm{P}_{2}$ (period of pain threshold to ES during administration of $\alpha$ hCRH) was significantly lower than that at $\mathrm{P}_{1}$ (period of pain threshold to ES during administration of saline; $\mathrm{p}=0.042$ ) (fig 5). In contrast, the ordinate scale of anxiety in controls did not change in the second stage of the experiment. The ordinate scale of stress showed a similar pattern to that of anxiety (data not shown).

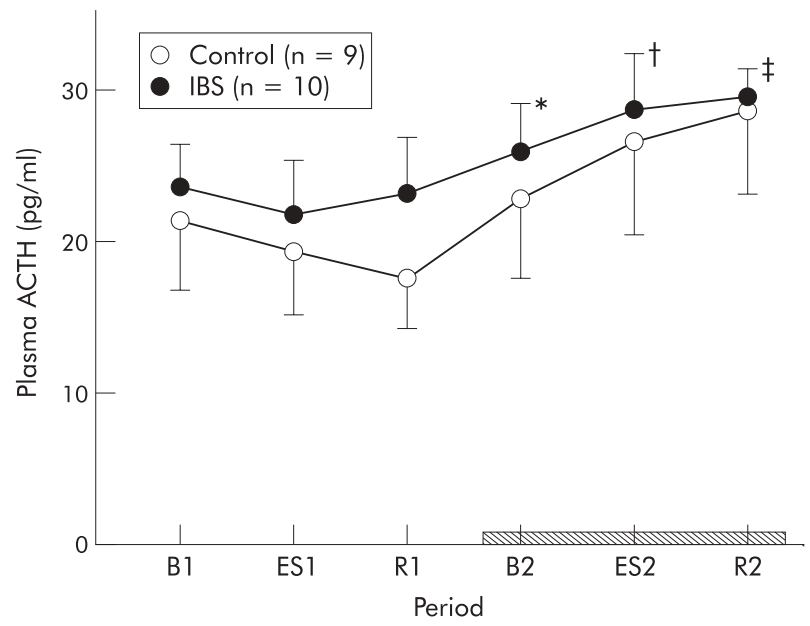

Figure 6 Changes in plasma adrenocorticotropic hormone (ACTH). B1: baseline, ES1: electrical stimulation of the rectum, and R1: recovery, in the first stage of the experiment. B2: baseline, ES2: electrical stimulation of the rectum, and R2: recovery, in the second stage (hatched bar). Data are expressed as mean (SEM). ACTH increased time dependently (two way ANOVA, period effect, $\mathrm{p}<0.0001$ ) in the second stage of the experiment and this increment was remarkable in irritable bowel syndrome (IBS) patients (from B1 to B2, ES2, and R2, ${ }^{*} p<0.05$, $\dagger p<0.05, \pm p<0.01$, respectively, Wilcoxon's signed rank test). Plasma ACTH in IBS patients tended to be higher than that in controls but no significant group to period interaction was detected.
Although the ordinate scale of sleepiness did not change significantly just after administration of $\alpha \mathrm{hCRH}, 14$ subjects (nine controls, five IBS patients) reported mild sleepiness and relaxed sensations (data not shown).

\section{Neuroendocrine data}

Administration of $\alpha$ hCRH failed to reduce ACTH levels in plasma as ACTH increased time dependently (two way ANOVA, period effect, $\mathrm{p}<0.0001$ ). However, plasma ACTH in IBS patients tended to be higher than that in controls (fig 6). No significant group to period interaction was indicated.

Two way ANOVA of serum cortisol revealed a significant period effect $(\mathrm{F}=3.16, \mathrm{p}=0.012)$. However, there was no significant difference in levels of serum cortisol between the two groups.

\section{DISCUSSION}

This is the first study to demonstrate that colonic function and visceral perception in IBS patients can be modified by peripheral administration of ahCRH, a non-selective CRH receptor antagonist. Earlier studies reported that $\mathrm{CRH}$ receptor antagonists inhibit gut motor alterations induced by stress..$^{910}$ In addition, exogenous CRH is known to exaggerate colonic motility and abdominal pain in IBS patients. ${ }^{18}$ Therefore, the present study provides strong support for the hypothesis that CRH signalling pathways play a key role in the pathophysiology of IBS.

In this study, ahCRH administration decreased colonic tone in control subjects but not in IBS patients. In fact, colonic tone in IBS patients increased throughout our experiment and was even exaggerated by electrical stimulation of the rectum. These phenomena may be explained by the physiological effect of CRH. Indeed, it has been reported that direct administration of CRH increases colonic intraluminal pressure and ejects fluid from colonic segments in vitro and that $\alpha$ hCRH blocks these effects in rats. ${ }^{28}$ Therefore, 
increased sensitivity of the gut to CRH in IBS patients may account for the above phenomena.

Our result showing increased colonic tone after transmucosal electrical stimulation of the gut in IBS patients is a partial replication of that of a previous report from our laboratory indicating that electrical stimulation produces different colonic responses in normal subjects and IBS patients. ${ }^{29}$ These findings may be explained by accommodative dysfunction of the colon or increased CRH tone in the brain of IBS patients. ${ }^{30}$ However, in this study, the dose of ahCRH $(10 \mu \mathrm{g} / \mathrm{kg})$ may not have been high enough to antagonise increased CRH action in the gut, brain, or both, in IBS patients.

Experimental stressors, ${ }^{16}{ }^{17}$ neostigmine, ${ }^{17}$ or CRH administration ${ }^{18}$ have been reported to increase the reactivity of the colon in IBS patients. In this study, the same phenomenon was replicated and administration of ahCRH blocked this response. It is therefore assumed that the CRH pathway is involved in the mechanism of increased phasic contractions of the colon in response to various stimuli in IBS patients. In this study, basal motility indices were influenced by prior mechanical distension. Mechanical distension of the gut is known to induce the peristaltic reflex and/or colo-colonic inhibitory reflex, and intense stimulation of the gut induces visceral sensation. ${ }^{31}$ Colonic distension has also been reported to produce exaggerated colonic motility among IBS patients. ${ }^{19}{ }^{32}$ Therefore, the decrease in motility indices of the colon in IBS patients after administration of ahCRH in this study may partially reflect inhibition of exaggerated phasic contractions of the colon by luminal distension.

The precise site of action of intravenously administered $\mathrm{CRH}$ antagonists on gastrointestinal function is unknown. Several subtypes of the CRH receptor have been reported. Among them, $\mathrm{CRH}_{1}$ is predominantly expressed in the brain and $\mathrm{CRH}_{2}$ in peripheral sites. ${ }^{33}{ }^{34}$ It has been reported that peripheral administration of CRH stimulates colonic motility, and that blockage of peripheral $\mathrm{CRH}_{1}$ receptors inhibits accelerated colonic motility. ${ }^{14}$ Blockage of the enteric nervous system (ENS) by tetrodotoxin or lidocaine also inhibits activation of colonic segments induced by $\mathrm{CRH}$ in vitro. ${ }^{28}$ Therefore, the decrease in motility indices of the colon in IBS patients after administration of $\alpha \mathrm{hCRH}$ in this study might be due to $\mathrm{CRH}_{1}$ antagonism of the ENS.

An earlier study reported decreased sensory thresholds (allodynia) and increased subjective sensation (hyperalgesia) to rectosigmoid distension in IBS patients. ${ }^{19}$ In this study, no overt allodynia was detected but hyperalgesia was replicated in IBS patients. Stimulation induced by gut distension is transmitted via unmyelinated C fibres, ${ }^{35}$ and gut ES is presumably transmitted via myelinated $A \delta$ fibres. ${ }^{36}$ In this study, ahCRH suppressed ES induced visceral sensation and normalised visceral hyperalgesia in IBS patients. Therefore, it is suggested that the CRH pathway might be involved, at least partially, in visceral hyperalgesia, which could be mediated via $\mathrm{A} \delta$ fibres.

Administration of $\alpha$ hCRH reduced anxiety induced by gut stimuli in IBS patients but not in control subjects. Moreover, ahCRH induced sleepiness in $70 \%$ of all subjects. It is thus plausible that peripheral administration of $\alpha$ hCRH influences the central nervous system either by decreased visceral input through blockage of peripheral CRH receptors or by a direct action of $\alpha \mathrm{hCRH}$ on the brain. There is a specific unidirectional brain to blood transporter system for $\mathrm{CRH},{ }^{37}$ and like CRH, ahCRH may not penetrate the brain. Therefore, intravenously administered ahCRH may affect the brain through CRH receptors ${ }^{38}$ at circumventricular organs that are relatively unprotected by the blood-brain barrier. This notion is supported by earlier reports indicating that intravenous administration of CRH influences sleep electroencephalo- grams in humans ${ }^{39}$ and that blockage of central CRH receptors reduces spontaneous waking. ${ }^{40}$

In this study, levels of plasma ACTH and serum cortisol were not suppressed by ahCRH $(10 \mu \mathrm{g} / \mathrm{kg})$. There are two possibilities for this result. One is that ahCRH has lower affinity for $\mathrm{CRH}_{1}$ receptors than for $\mathrm{CRH}_{2}$ receptors. ${ }^{41}$ The other is that the dose of $\alpha \mathrm{hCRH}$ used in this study, although it improved visceral hyperalgesia in IBS patients, was not high enough to completely block $\mathrm{CRH}$ receptors in the pituitary gland.

In conclusion, intravenous administration of $\alpha$ hCRH alters colonic function and reduces symptoms induced by rectal electrical stimulation in IBS patients, with no inhibitory effects on the hypothalamo-pituitary-adrenal axis. These data suggest that CRH may play an important role in the pathophysiology of IBS.

\section{Authors' affiliations}

Y Sagami, T Nomura, M Satake, Y Endo, T Shoji, K Karahashi, Department of Psychosomatic Medicine, Tohoku University School of Medicine, Sendai, Japan

Y Shimada, J Tayama, S Fukudo, Department of Behavioural Medicine, Tohoku University School of Medicine, Sendai, Japan

M Hongo, Department of Comprehensive Medicine, Tohoku University School of Medicine, Sendai, Japan

\section{REFERENCES}

1 Vale W, Spiess J, Rivier C, et al. Characterization of a 41-residue ovine hypothalamic peptide that stimulates secretion of corticotropin and $\beta$ endorphin. Science 1981;213:1394-7.

2 Petrusz P, Merchenthaler I. The corticotropin-releasing factor system. In: Nemeroff CB, eds. Neuroendocrinology. Boca Raton, Florida: CRC Press, 1992:129-83.

3 Dunn AJ, Berridge CW. Physiological and behavioral responses to corticotropin-releasing factor administration: is CRF a mediator of anxiety or stress responses? Brain Res Rev 1990;15:71-100.

4 Owens MJ, Nemeroff CB. Physiology and pharmacology of corticotropinreleasing factor. Pharamacol Rev 1991;43:425-73.

5 Tache Y, Mönnikes H, Rivier J, et al. Role of CRF in stress-related alterlations of gastric and colonic motor function. Ann N Y Acad Sci 1993:697:233-43.

$6 \mathrm{Koo}$ MW, Ogle CW, Cho $\mathrm{CH}$. The effect of cold restraint stress on gastric emptying in rats. Pharmacol Biochem Behav 1985;23:969-72.

7 Barquist E, Zinner M, Rivier J, et al. Abdominal surgery-induced delayed gastric emptying in rats: role of CRF and sensory neurons. Am J Physiol 1992;262:G616-20.

8 Barone FC, Deegan JF, Price WJ, et al. Cold-restraint stress increases rat fecal pellet output ant colonic transit. Am J Physiol 1990;258:G329-37.

9 Mönnikes H, Schmidt BG, Tache Y. Psychological stress-induced accelerated colonic transit in rats involves hypothalamic corticotropin-releasing factor. Gastroenterology 1993;104:716-23.

10 Gue M, Junien JL, Bueno L. Conditioned emotional response in rats enhances colonic motility the central release of corticotropin-releasing factor. Gastroenterology 1991;100:964-70.

11 Mönnikes H, Schmidt BG, Raybould HE, et al. CRF in the paraventricular nucleus mediates gastric and colonic motor response to restraint stress. Am J Physiol 1992;262:G137-43.

12 Mönnikes H, Schmidt BG, Tache Y. Microinfusion of corticotropin-releasing factor into the locus coeruleus/subcoeruleus nuclei stimulates colonic motor function in rat. Brain Res 1994:644:101-8.

13 Martinez V, Rivier J, Wang L, et al. Central injection of a new CRF antagonist, astressin, blocks CRF- and stress-related alterations of gastric and colonic motor function. J Pharmacol Exp Ther 1997;280:754-60.

14 Maillot C, Million M, Wei JY, et al. Peripheral corticotropin-releasing factor and stress-stimulated colonic motor activity involve type 1 receptor in rats. Gastroenterology 2000;119:1569-79.

15 Drossman DA, Ritcher JE, Talley NJ. The functional gastrointestinal disorders. Boston: Little, Brown \& Co, 1994.

16 Fukudo S, Suzuki J. Colonic motility, autonomic function, and gastrointestinal hormones under psychological stress on irritable bowel syndrome. Tohoku J Exp Med 1987; 151:373-85.

17 Fukudo S, Nomura T, Muranaka M, et al. Brain-gut response to stress and cholinergic stimulation in irritable bowel syndrome. J Clin Gastroenterol 1993;17:133-41.

18 Fukudo S, Nomura T, Hongo M. Impact of corticotropin-releasing hormone on gastrointestinal motility and adrenocorticotropic hormone in normal controls and patients with irritable bowel syndrome. Gut 1998;42:845-9.

19 Whitehead WE, Holtkotter B, Enck P, et al. Tolerance for rectosigmoid distention in irritable bowel syndrome. Gastroenterology 1990:98:1187-92.

20 Lembo T, Plourde V, Shui Z, et al. Effect of the corticotropin-releasing factor (CRF) on rectal afferent nerves in humans. Neurogastroenterol Mot 1996;8:9-18. 
21 Whitehead WE, Schuster MM. Irritable bowel syndrome: Definition of the syndrome and relation to other disorders. Physiological and psychologica mechanism. In, Whitehead WE, Schuster MM, eds. Gastrointestinal disorders: behavioral and physiological basis for treatment New York, Academic Press, 1985:155-209.

22 Gorard DA, Gomborone JE, Farthing MJ. Intestinal transit in anxiety and depression. Gut 1996;39:551-5

23 Thompson WG, Longstreth GF, Drossman DA, et al. Functional bowel disorders and functional abdominal pain. Gut 1999:45(suppl II):43-7.

24 Lemann M, Flourie B, Picon L, et al. Motor activity recorded in the unprepared colon of healthy humans. Gut 1995;37:649-53

25 Whitehead WE, Delvaux M. Standardization of barostat procedures for testing smooth muscle tone and sensory thresholds in the gastrointestinal tract. The working team of Glaxo-Wellcome research, UK. Dig Dis Sci 1997:42:223-41.

26 Fukudo S, Kotake $M$, Sagami $Y$, et al. Exaggerated viscerosensory evoked potentials in irritable bowel syndrome. Gastroenterology 2001;120:A4032

27 Bazzocchi G, Ellis J, Villanueva-Meyer J, et al. Postprandial colonic transit and motor activity in chronic constipation. Gastroenterology 1990:98:686-93.

28 Mancinelli R, Azzena GB, Diana M, et al. In vitro excitatory actions of corticotropin-releasing factor on rat colonic motility. J Auton Pharmacol 1998; 18:319-24.

29 Fukudo $S$, Hongo $M$, Kanazawa $M$, et al. Colonic response to transmucosal electrical stimulation is impaired in patients with irritable bowel syndrome. Gastroenterology 1997;112:A1148.

30 Blomhoff S, Spetalen S, Jacobsen MB, et al. Rectal tone and brain information processing in irritable bowel syndrome. Dig Dis Sci 2000;45:1153-9.

31 Davison JS. Inneration of the gastrointestinal tract. In: Christensen J, Wingate DL, eds. A guide to gastrointestinal motility. Bristol: Wright 1983:1-47
32 Fukudo S, Kanazawa $M$, Kano $M$, et al. Exaggerated motility of the descending colon with repetitive distention of the sigmoid colon in patients with irritable bowel syndrome. J Gastrenterol 2002;37(suppl 14):145-50.

33 Lovenberg TW, Chalmers DT, Liu C, et al. CRF2 alpha and CRF2 beta receptor mRNAs are differentially distributed between the rat central nervous system and peripheral tissues. Endocrinology 1995;136:4139-42.

34 Hiroi N, Wong ML, Licinio J, et al. Expression of corticotropin releasing hormone receptors type I and type II mRNA in suicide victims and controls. Mol Psychiatry 2001;6:540-6.

35 Castell DO, Wood JD, Frieling T, et al. Cerebral electrical potentials evoked by balloon distention of the human esophagus. Gastroenterology 1990;98:662-6.

36 Tougas G, Hudoba P, Fitzpatrick D, et al. Cerebral-evoked potential responses following direct vagal and esophageal electrical stimulation in humans. Am J Physiol 1993;264:G486-91.

37 Martins JM, Kastin AJ, Banks WA. Unidirectional specific and modulated brain to blood transport of corticotropin-releasing hormone. Neuroendocrinology 1996;63:338-48.

38 Perrin MH, Donaldson CJ, Chen R, et al. Cloning and functional expression of a rat brain corticotropin releasing factor (CRF) receptor. Endcrinology 1993:133:3058-61.

39 Holsboer F, Bardeleben U, Steiger A. Effects of intravenous corticotropinereleasing hormone upon sleep-related growth hormone surge and sleep EEG in man. Neuroendocrinology 1988:48:32-8.

40 Chang FC, Opp MR. Blockade of corticotropin-releasing hormone receptors reduces spontaneous waking in the rat. Am J Physiol 1998;275:R793-802.

41 Perrin MH, Sutton SW, Cervini LA, et al. Comparison of an agonist, urocortin, and an antagonist, astressin, as radioligands for characterization of corticotropin-releasing factor receptors. J Pharmacol Exp Ther 1999;288:729-34.

\section{EDITOR'S QUIZ: GI SNAPSHOT}

\section{An unusual case of bowel obstruction Clinical presentation}

A healthy 81 year old man was referred to us for acute bowel obstruction. The patient did not have a history of chronic illness and was not taking any medication.

On admission, the patient had diffuse abdominal pain, vomiting, and no bowel movements for 24 hours. There was no fever. Clinical examination showed abdominal distension without any contracture or palpable mass. Laboratory data were as follows: leucocyte count $11000 / \mathrm{mm}^{3}$ and haemoglobin level $15 \mathrm{~g} / \mathrm{dl}$. C reactive protein concentration was increased to $235 \mathrm{mg} / \mathrm{l}$. Hepatic function tests and amylasemia were normal. Abdominal $x$ ray showed small bowel distension with hydroaeric levels (Image 1). Small bowel barium through enema was performed and the results are shown below.

\section{Question}

What does this $x$ ray show?

See page 979 for answer

This case is submitted by:

I Rosa, J Serpaggi, I Delacroix, H Hagège, M Chousterman Department of Internal Medicine and Hepatogastroenterology, Hôpital Intercommunal de Créteil, 94010 Créteil, France

I Bitar, P Cabanis Department of Surgery, Hôpital Intercommunal de Créteil, 94010 Créteil, France

B Poulet, I A B D Alsamad

Department of Anatomopathology, Hôpital Intercommunal de Créteil, 94010 Créteil, France

Correspondence to: Dr Isabelle Rosa, Department of Internal Medicine and Hepatogastroenterology, Hôpital Intercommunal de Créteil, 94010 Créteil, France; e-mail: isabelle.rosa@chicreteil.fr doi: 10.1136/gut.2003.02895
Robin Spiller, Editor

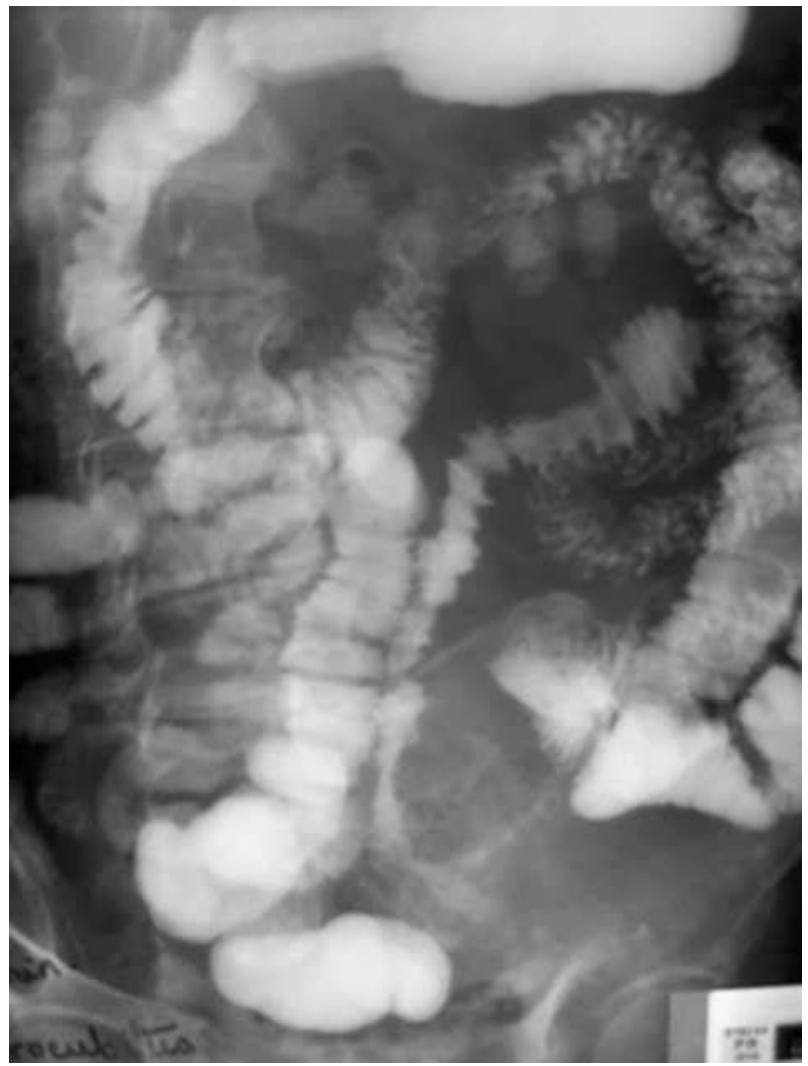

Image 1 Abdominal $x$ ray showing small bowel distension with hydroaeric levels. 